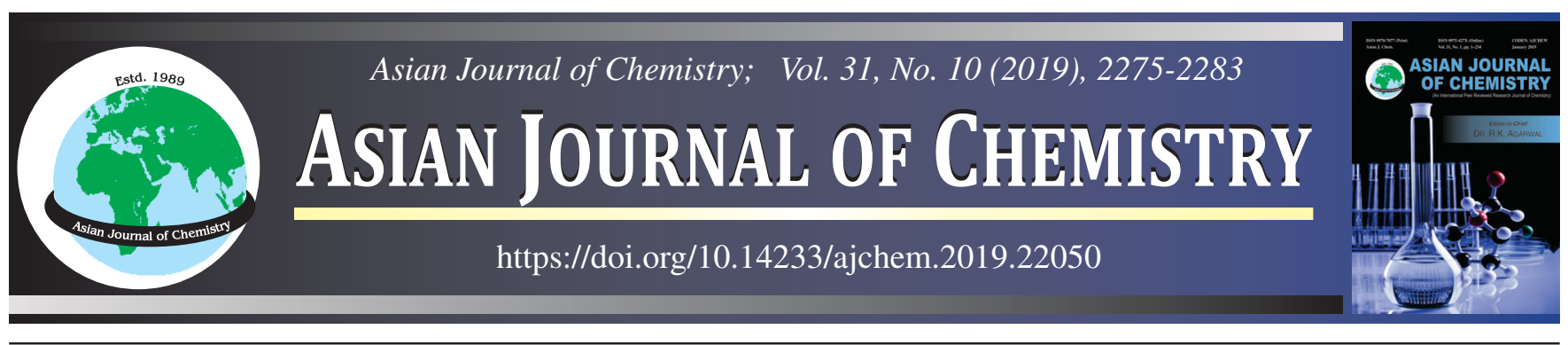

\title{
HPLC Method for Determination of Aspirin, Rosuvastatin, Ezetimibe and Clopidogrel in Combination Drug Products
}

\author{
Suresh Kumar Palacharla* and G.V. Krishna Mohan
}

Department of Chemistry, K.L. University, Green Fields, Vaddeswaram-522502, India

*Corresponding author: E-mail: palacharla.suresh@gmail.com

Received: 5 March 2019;

Accepted: 22 May 2019;

Published online: 30 August 2019;

AJC-19535

A single HPLC method for the determination of four active ingredients viz. aspirin, rosuvastatin, ezetimibe and clopidogrel in less run time is developed. HPLC method was developed and validated. X-terra C18 $100 \times 4.6 \mathrm{~mm}, 3.5 \mu \mathrm{HPLC}$ column, $\mathrm{KH}_{2} \mathrm{PO}_{4}$ buffer (mobile phase A) and acetonitrile (mobile phase B) were used. $20 \mu$ injection volume, $1.0 \mathrm{~mL} / \mathrm{min}$ flow rate, $230 \mathrm{~nm}$ and ambient column oven temperature were applied for separation. Gradient program: at 0 min mobile phase-B $13 \%$, at 4 min $13 \%$, at 8 min $44 \%$, 14 min $57 \%$, $17 \min 57 \%$, 20 min $13 \%$ and 25 min $13 \%$. Method validation was performed as per ICH guidance with precision, linearity, specificity, accuracy, ruggedness and robustness. Validation results were satisfactory and this method can be applied for regular drug product manufacturing.

Keywords: Aspirin, Clopidogrel, Ezetimibe, Rosuvastatin, HPLC method.

ᄂ ----------------------------------$\lrcorner$

\section{INTRODUCTION}

Aspirin is used treat pain, inflammation and fever. Aspirin can be given shortly after the heart attack decreases the risk of health and also used for long term to prevent heart attacks, ischaemic strokes and blood clots [1,2]. If we use over dose it may give side effects stomach upset like stomach ulcers, stomach bleeding and asthma [3].

Rosuvastatin belongs to statins group and used for high blood cholesterol, cardiovascular disease. Body LDL cholesterol were reduced and this control effects dose related [4]. Higher dose of rosuvastatin has more efficacious in improving lipid profile of patients with hypercholesterolemia. Few studies were confirmed the moderately increasing of HDL by using rosuvastatin [5]. Side effects are constipation, dizziness, sleeplessness, depression, joint pain, cough, memory loss and heartburn.

Ezetimibe can reduce the cholesterol levels. Ezetimibe is used with statins to achieve the target LDL cholesterol levels [6]. Ezetimibe inhibits the absorption of cholesterol from the small intestine and decreases the quantity of cholesterol. Common adverse effects are headache, diarrhea and myalgia [7]. Clopidogrel reduces the heart disease and heart strokes. Clopidogrel brand name is plavix and also used with aspirin combin- ation product $[8,9]$. Clopidogrel is used for acute coronary syndrome, stroke and peripheral artery disease [10].

Chemical structures of aspirin, rosuvastatin, ezetimibe and clopidogrel were represented in Fig. 1. Clopidogrel is available with aspirin and rosuvastatin combinations and rosuvastatin is available with ezetimibe combination dosage form. Table-1 is listed the all available combination products in the market.

Literature survey found less methods to determine the clopidogrel, aspirin and some are reported for ezetimibe and rosuvastatin [11,12] only. Some authors [13-15] reported rosuvastatin and ezetimibe in pharmacokinetic studies. Main objective of this study was to develop a single HPLC method to determine aspirin, rosuvastatin, ezetimibe and clopidogrel in tablets dosage form.

\section{EXPERIMENTAL}

A high performance liquid chromatograph of Agilent make 1100 series auto sampler instrument was used. Analytical data was recorded using empower work station. Analytical experiments were performed on a stainless steel column Xterra MS-C18: $100 \times 3.0 \mathrm{~mm} ; 5 \mu \mathrm{m}$ with the mobile phase gradient programmed elution. A $30^{\circ} \mathrm{C}$ column oven tempe-

This is an open access journal, and articles are distributed under the terms of the Attribution 4.0 International (CC BY 4.0) License. This license lets others distribute, remix, tweak, and build upon your work, even commercially, as long as they credit the author for the original creation. You must give appropriate credit, provide a link to the license, and indicate if changes were made. 
<smiles>CC(=O)Oc1ccccc1C(=O)O</smiles>

Aspirin<smiles>CC(C)c1nc(N(C)S(C)(=O)=O)nc(-c2ccc(F)cc2)c1/C=C/[C@@H](O)C[C@@H](O)CC(=O)O</smiles>

Rosuvastatin<smiles>O=C1[C@H](CC[C@H](O)c2ccc(F)cc2)[C@H](c2ccc(O)cc2)N1c1ccc(F)cc1</smiles>

Ezetimibe<smiles>COC(=O)[C@H](c1ccccc1Cl)N1CCc2sccc2C1</smiles>

Clopidogrel

Fig. 1. Chemical structure of aspirin, rosuvastatin, ezetimibe and clopidogrel

\begin{tabular}{|c|c|}
\hline \multicolumn{2}{|c|}{$\begin{array}{c}\text { TABLE-1 } \\
\text { MARKETED COMBINATION PRODUCTS }\end{array}$} \\
\hline Combination products & Manufacturing company name \\
\hline Aspirin $75 \mathrm{mg}+$ Clopidogrel $75 \mathrm{mg}$ & Blue cross, Emcure, AS pharmaceuticals, Macleods, Biocon, Aristo \\
\hline Rosuvastatin $10 \mathrm{mg}+$ Clopidogrel $75 \mathrm{mg}$ & Macleods, Vidakem Lifesciences \\
\hline Rosuvastatin $10 \mathrm{mg}+$ Clopidogrel $75 \mathrm{mg}+$ Aspirin $75 \mathrm{mg}$ & Macleods \\
\hline Rosuvastatin $10 \mathrm{mg}+$ Ezetimibe $10 \mathrm{mg}$ & Glenmark, Lupin, Ranbaxy \\
\hline
\end{tabular}

rature was used. Flow rate was kept at $1.0 \mathrm{~mL} / \mathrm{min}$, and the elution was monitored at $230 \mathrm{~nm}$. Injection volume is $20.0 \mu \mathrm{L}$.

Mobile phase A: Potassium dihydrogen orthophosphate $\left(\mathrm{KH}_{2} \mathrm{PO}_{4}, 6.8 \mathrm{~g}\right)$ was weighed accurately and transferred into a $1 \mathrm{~L}$ mobile phase preparation beaker containing $1000 \mathrm{~mL}$ Milli-Q-water. Mixed well with stirring, further degassed the buffer solution through $0.45 \mu \mathrm{m}$ filter paper using vacuum pump.

Mobile phase B: Analytical grade acetonitrile was used.

Diluent solution preparation: Mixed the mobile phase A and analytical grade acetonitrile in the ratio of 50:50 v/v. The gradient program is mentioned in Table- 2 .

\begin{tabular}{ccc}
\multicolumn{3}{c}{ TABLE-2 } \\
GRADIENT PROGRAM \\
\hline Time (min) & Mobile phase A (\%) & Mobile phase B (\%) \\
\hline 0.01 & 87 & 13 \\
4.0 & 87 & 13 \\
8.0 & 56 & 44 \\
14.0 & 43 & 57 \\
17.0 & 43 & 57 \\
20.0 & 87 & 13 \\
25.0 & 87 & 13 \\
\hline
\end{tabular}

Ezetimibe and rosuvastatin standard stock solution: Placed accurately weighed $50 \mathrm{mg}$ of rosuvastatin, ezetimibe standard compounds into a $100 \mathrm{~mL}$ volumetric flask, diluent was added to dissolve and sonicated to reach the clear solution and made up to the volume with diluent.

Aspirin and clopidogrel standard stock solution: A 75 mg of clopidogrel and aspirin standard materials were weighed precisely and transferred into a $100 \mathrm{~mL}$ volumetric flask. Diluent $(50 \mathrm{~mL})$ was added and mixed to dissolve. Further volume was diluted with diluent.

Standard solution: Rosuvastatin-ezetimibe standard stock (1 mL) and clopidogrel-aspirin standard solutions (5 mL) were pipetted and transferred into a $50 \mathrm{~mL}$ volumetric flask and diluted with diluent.

Aspirin, clopidogrel and rosuvastatin test solution: Twenty tablets were weighed and made the fine powder with mortar and pestle. Equivalent to $75 \mathrm{mg}$ of clopidogrel test sample (equivalent to $75 \mathrm{mg}$ aspirin, $10 \mathrm{mg}$ rosuvastatin) was weighed accurately and transferred into a $100 \mathrm{~mL}$ class A volumetric flask. Then, $25 \mathrm{~mL}$ of diluent solution was added and sonicated for $15 \mathrm{~min}$ and made up to the volume with diluent solution and mixed well. Further, $5 \mathrm{~mL}$ of resulting solution was pipetted and transferred into a $50 \mathrm{~mL}$ volumetric flask and diluted with diluent.

Ezetimibe and rosuvastatin test solution: Twenty tablets were weighed and made the fine powder with mortar and pestle. Equivalent to $10 \mathrm{mg}$ of rosuvastatin and ezetimibe test sample was weighed accurately and transferred into a $100 \mathrm{~mL}$ class A volumetric flask. Then, $25 \mathrm{~mL}$ of diluent solution was added and sonicated for $15 \mathrm{~min}$ and made up the volume with diluent solution and mixed well. Further, $1 \mathrm{~mL}$ of solution pipetted and transferred into a $50 \mathrm{~mL}$ volumetric flask and diluted with diluent.

System suitability limits: The \% RSD for the peaks area of each component for six replicate injections of $2.0 \%$, peak theoretical plates should be more than 2000 and tailing factor should be not more than 2.0 .

\section{RESULTS AND DISCUSSION}

Ezetimibe, rosuvastatin, aspirin and clopidogrel were well separated by using simple chromatographic conditions. Method optimization was started based on the solubility, UV absorbance and FT-IR studies.

Method development: All the four ingredients solubility studies were performed with water, acetonitrile and methanol individual solutions and mixed solutions. Aspirin, rosuvastatin, ezetimibe and clopidogrel UV spectral studies were performed. All the four compounds have maximum absorbance from 220 to $235 \mathrm{~nm}$. However, $230 \mathrm{~nm}$ was selected for method development and validation. Fig. 2 represented the UV spectrum of four compounds.

Method development trial-1: Conditions: (a) A $3.4 \mathrm{~g}$ of $\mathrm{K}_{2} \mathrm{HPO}_{4}$ in $1000 \mathrm{~mL}$ of water used as buffer; (b) buffer and acetonitrile $80: 20 \mathrm{v} / \mathrm{v}$ used as mobile phase A; (c) acetonitrile used as mobile phase $\mathrm{B}$; (d) Zorbax $\mathrm{C}_{18} 150 \times 4.6 \mathrm{~mm}, 5 \mu$ column; (e) flow rate $1.0 \mathrm{~mL} / \mathrm{min}, 30{ }^{\circ} \mathrm{C}$ column temperature, $230 \mathrm{~nm}$; 

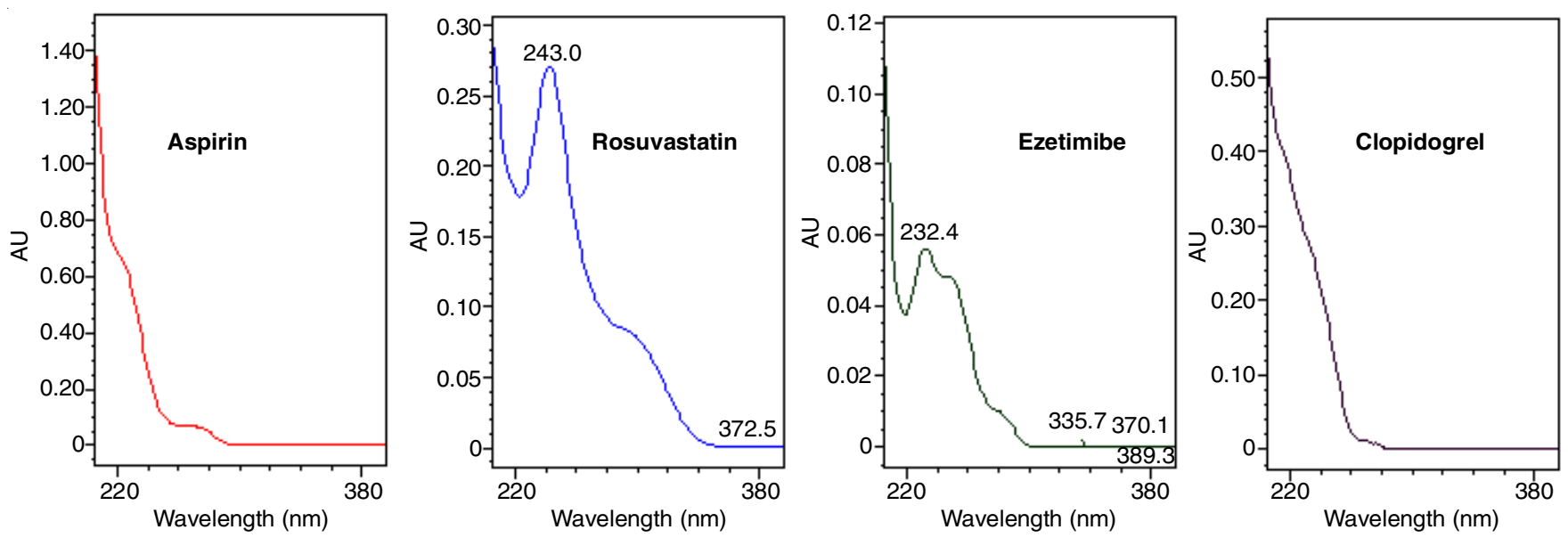

Fig. 2. UV spectra of aspirin, rosuvastatin, ezetimibe and clopidogrel

(f) gradient program at 0 min $20 \%$ mobile phase B at 10 min $43 \%$, at $15 \min 83 \%$, at $25 \min 83 \%$, at $28 \mathrm{~min} 20 \%$ and at 35 min $20 \%$; (g) diluent: water and acetonitrile 45:55 v/v.

Observations: Elution of four compounds was aspirin at $2.8 \mathrm{~min}$, rosuvastatin at $7.7 \mathrm{~min}$, ezetimibe $11.7 \mathrm{~min}$ and clopidogrel $20.7 \mathrm{~min}$. Mixed sample also injected into the HPLC system but peak shape was poor. Further method optimization can be performed with different column, mobile phase elution. Figs. 3-6 were represented the individual chromatogram of four components while Fig. 7 represented the mixed sample chromatogram.

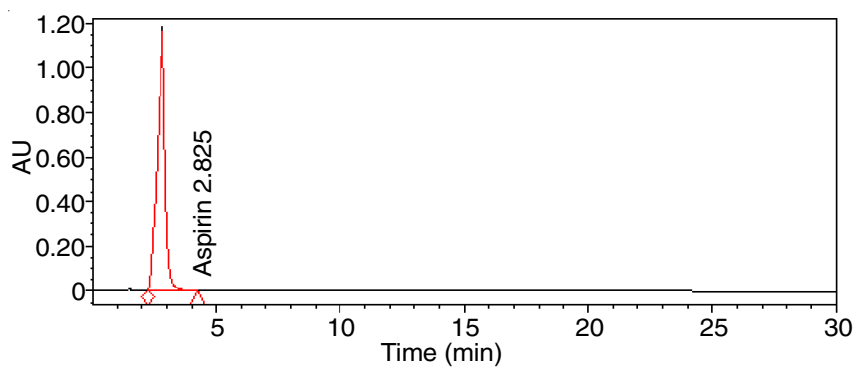

Fig. 3. Chromatogram of aspirin

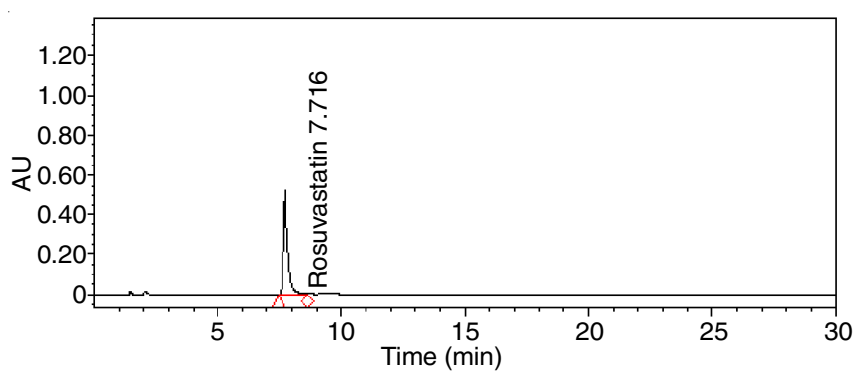

Fig. 4. Chromatogram of rosuvastatin

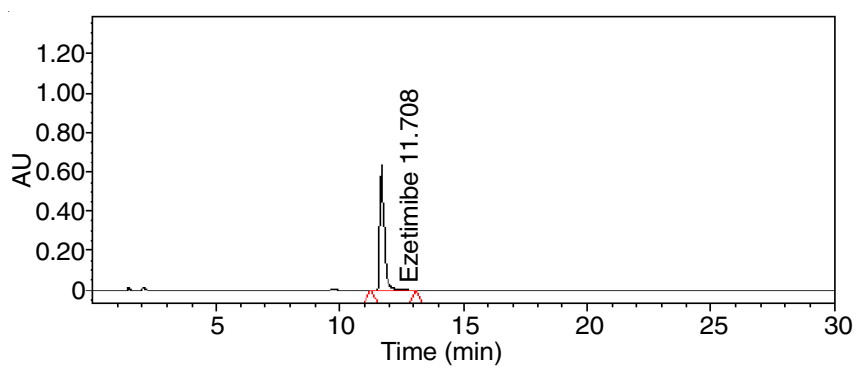

Fig. 5. Chromatogram of ezetimibe

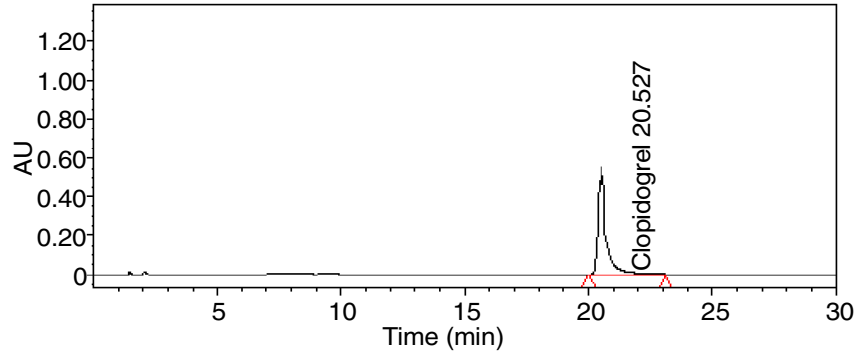

Fig. 6. Chromatogram of clopidogrel

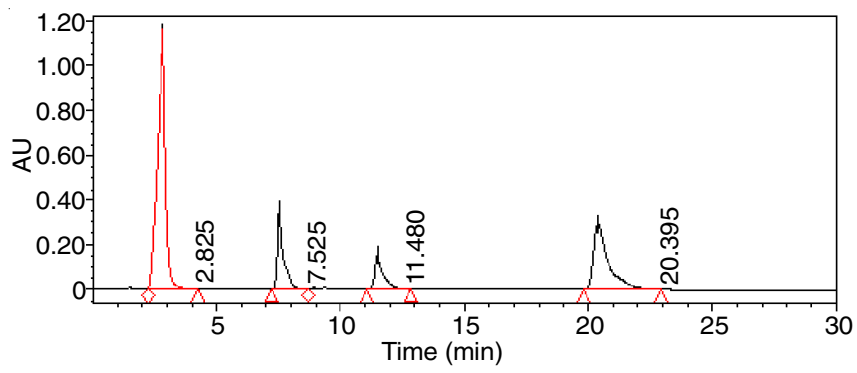

Fig. 7. Development trial chromatogram

Method development trial-2: Conditions: (a) A $6.8 \mathrm{~g}$ of $\mathrm{K}_{2} \mathrm{HPO}_{4}$ in $1000 \mathrm{~mL}$ of water used as buffer; (b) buffer and acetonitrile $80: 20 \mathrm{v} / \mathrm{v}$ used as mobile phase $\mathrm{A}$; (c) acetonitrile used as mobile phase $\mathrm{B}$; (d) Ace $\mathrm{C}_{18} 150 \times 4.6 \mathrm{~mm}, 5 \mu$ column; (e) flow rate $1.0 \mathrm{~mL} / \mathrm{min}, 30^{\circ} \mathrm{C}$ column temperature, $230 \mathrm{~nm}$; (f) gradient program at $0 \mathrm{~min} 25 \%$ mobile phase B, at $10 \mathrm{~min}$ $45 \%$, at $15 \mathrm{~min} 80 \%$, at $25 \mathrm{~min} 80 \%$, at $28 \mathrm{~min} 25 \%$ and at $35 \mathrm{~min} 25 \%$; (g) diluent: water and acetonitrile 45:55 v/v.

Observations: All the four components were separated but aspirin was eluted with unknown peak split. Fig. 8 represented the development trial chromatogram. Further optimization required get sharp peaks and no interference.

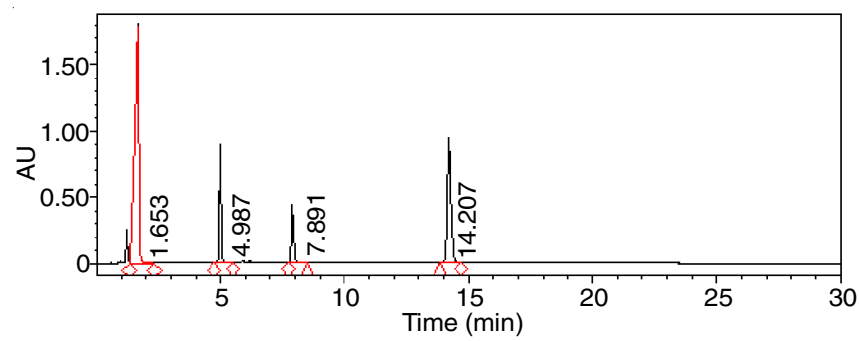

Fig. 8. Development trial chromatogram 
Method development trial-3: Conditions: (a) A $6.8 \mathrm{~g}$ of $\mathrm{K}_{2} \mathrm{HPO}_{4}$ in $1000 \mathrm{~mL}$ of water used as buffer; (b) buffer used as mobile phase $\mathrm{A}$; (c) acetonitrile used as mobile phase $\mathrm{B}$; (d) X-Terra MS $\mathrm{C}_{18} 100 \times 4.6 \mathrm{~mm}, 5 \mu$ column; (e) flow rate $1.0 \mathrm{~mL} / \mathrm{min}, 30^{\circ} \mathrm{C}$ column temperature, $230 \mathrm{~nm}$; (f) gradient program at $0 \min 13 \%$ mobile phase $\mathrm{B}$, at $4 \mathrm{~min} 13 \%$, at 8 $\min 44 \%$, at $14 \min 57 \%$, at $17 \min 57 \%$; at $20 \min 13 \%$; and at $25 \mathrm{~min} 13 \%$; (g) diluent: mobile phase $\mathrm{A}$ and acetonitrile $50: 50 \mathrm{v} / \mathrm{v}$.

Observations: In this development trial, all the four ingredients were well separated. Aspirin eluted at $2.6 \mathrm{~min}$, rosuvastatin at $9.5 \mathrm{~min}$, ezetimibe at $11.0 \mathrm{~min}$ and clopidogrel at $17.0 \mathrm{~min}$ (Fig. 9). The peak tailing factor, theoretical plates results were satisfactory so this development trial conditions were finalized.

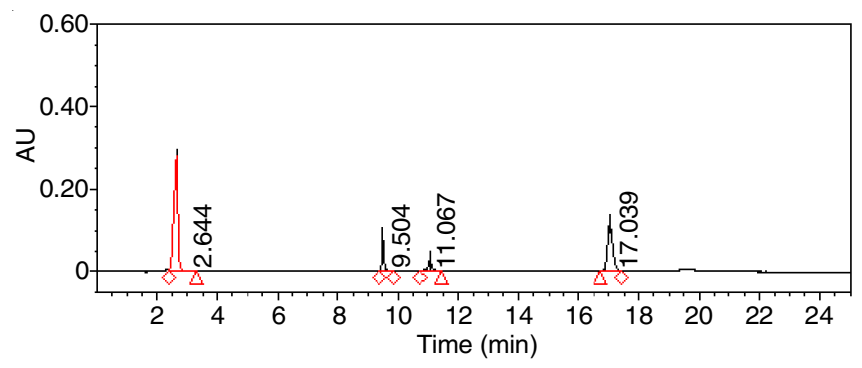

Fig. 9. Development trial chromatogram

Method validation: Method validation was performed as per ICH Q2 and USFDA guidelines. System suitability, precision, linearity, accuracy, ruggedness, robustness parameters were evaluated.

System suitability: System suitability was performed by preparing fresh standard solution and blank, placebo samples. Finalized chromatographic conditions were applied. Standard peak $\%$ area, tailing factor, theoretical plates were measured and tabulated in Table-3. Fig. 10 represented the five replicate standard stack chromatogram. The results were satisfactory i.e. tailing factor value is not more than 2.0; area \% RSD is not more than $2.0 \%$ and theoretical plates were above 2000 .
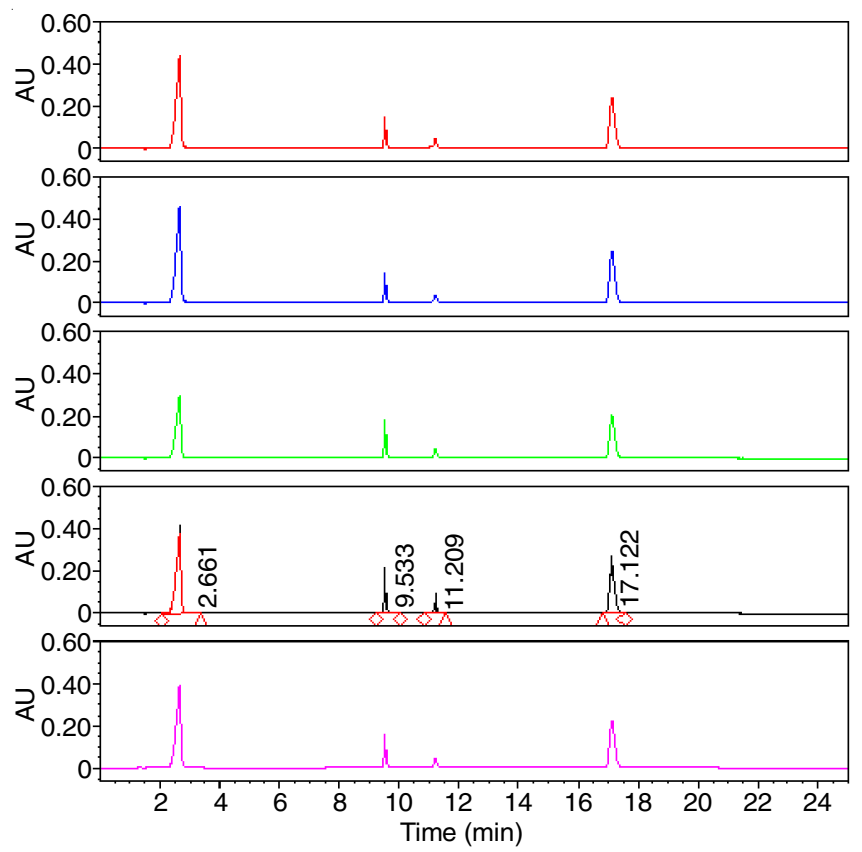

Fig. 10. System suitability five replicate standard chromatograms

Precision: Method precision and system precision was performed with six replicate freshly prepared test solutions. Clopidogrel, rosuvastatin, aspirin tablets were used to prepare three drug test sample solutions. Rosuvastatin and ezetimibe combination tablets were used to prepare test sample solution. Six replicate test solutions were prepared and injected in to the chromatographic system. Precision results \%RSD for six replicate solutions assay values were calculated and results (NMT $2.0 \%$ ) found to be satisfactory (Table-4). Figs. 11-15 represented the blank, placebo, test samples chromatograms.

Specificity: Specificity was performed by evaluating placebo and force degradation impurity peaks interference with four components. Specificity conditions are results are listed in Tables 5 and 6. Figs. 16-29 represented the overlay chromatograms with blank, placebo and force degradation studies.

Linearity: Method validation parameter linearity was performed with 50, 75, 100, 125 and $150 \%$ linearity levels. Freshly

\begin{tabular}{|c|c|c|c|c|c|c|c|c|}
\hline \multicolumn{9}{|c|}{$\begin{array}{c}\text { TABLE-3 } \\
\text { SYSTEM SUITABILITY RESULTS }\end{array}$} \\
\hline \multirow[t]{2}{*}{ S. No. } & RT (min) & Area & $\begin{array}{l}\text { Tailing } \\
\text { factor }\end{array}$ & $\begin{array}{l}\text { Theoretical } \\
\text { plates }\end{array}$ & RT (min) & Area & $\begin{array}{l}\text { Tailing } \\
\text { factor }\end{array}$ & $\begin{array}{c}\text { Theoretical } \\
\text { plates }\end{array}$ \\
\hline & \multicolumn{4}{|c|}{ Aspirin } & \multicolumn{4}{|c|}{ Rosuvastatin } \\
\hline 1 & 2.66 & 4532933 & 1.1 & 7532 & 9.53 & 626631 & 1.3 & 4936 \\
\hline 2 & 2.68 & 4526981 & 1.0 & 7562 & 9.53 & 621956 & 1.2 & 4864 \\
\hline 3 & 2.70 & 4519637 & 1.2 & 7621 & 9.52 & 628148 & 1.0 & 4868 \\
\hline 4 & 2.68 & 4521524 & 1.1 & 7534 & 9.56 & 628143 & 1.1 & 4876 \\
\hline 5 & 2.67 & 4534571 & 1.3 & 7519 & 9.50 & 625831 & 1.2 & 4839 \\
\hline Avg. & 2.68 & 4527129 & & & 9.53 & 626141 & & \\
\hline \multirow[t]{2}{*}{$\%$ RSD } & 0.55 & 0.15 & Avg. 1.14 & Avg. 7553 & 0.23 & 0.41 & Avg. 1.16 & Avg. 4876 \\
\hline & \multicolumn{4}{|c|}{ Ezetimibe } & \multicolumn{4}{|c|}{ Clopidogrel } \\
\hline 1 & 11.20 & 259103 & 1.1 & 5163 & 17.12 & 2769953 & 1.3 & 7361 \\
\hline 2 & 11.23 & 258169 & 1.3 & 5264 & 17.14 & 2759684 & 1.0 & 7237 \\
\hline 3 & 11.25 & 257996 & 1.2 & 5282 & 17.19 & 2761632 & 1.2 & 7264 \\
\hline 4 & 11.15 & 258134 & 1.0 & 5461 & 17.16 & 2764851 & 1.3 & 7315 \\
\hline 5 & 11.23 & 258162 & 1.1 & 5348 & 17.31 & 2731589 & 1.1 & 7196 \\
\hline Avg. & 11.21 & 258312 & & & 17.18 & 2757541 & & \\
\hline$\%$ RSD & 0.35 & 0.17 & Avg. 1.14 & Avg. 5303 & 0.44 & 0.54 & Avg. 1.18 & Avg. 7274 \\
\hline
\end{tabular}




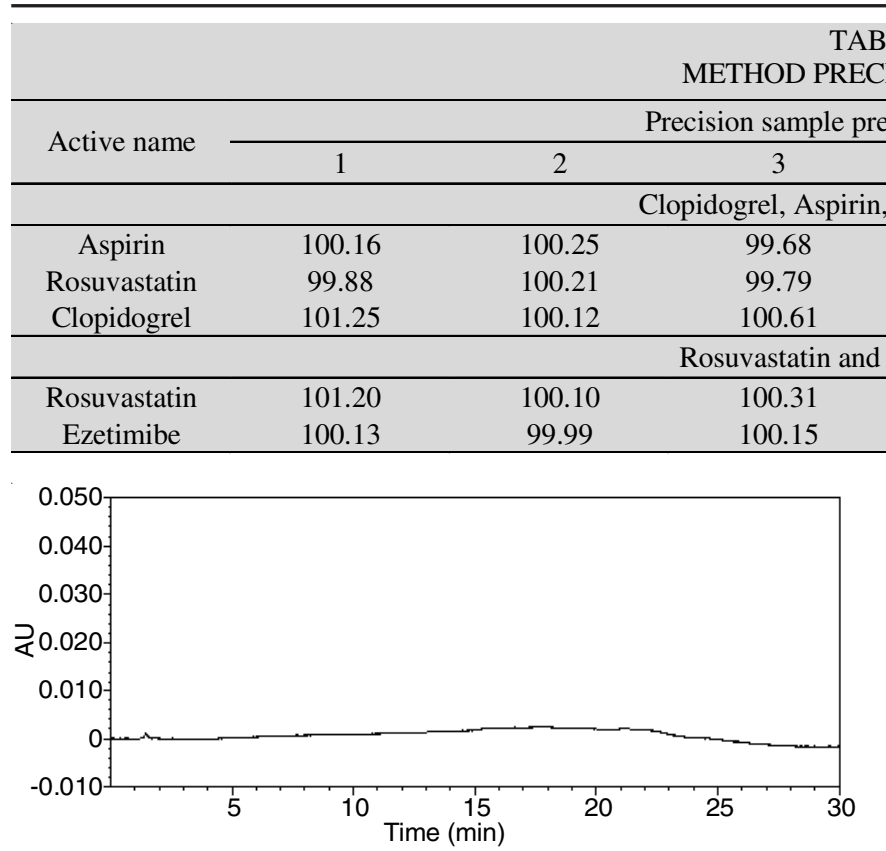

Fig. 11. Blank chromatogram

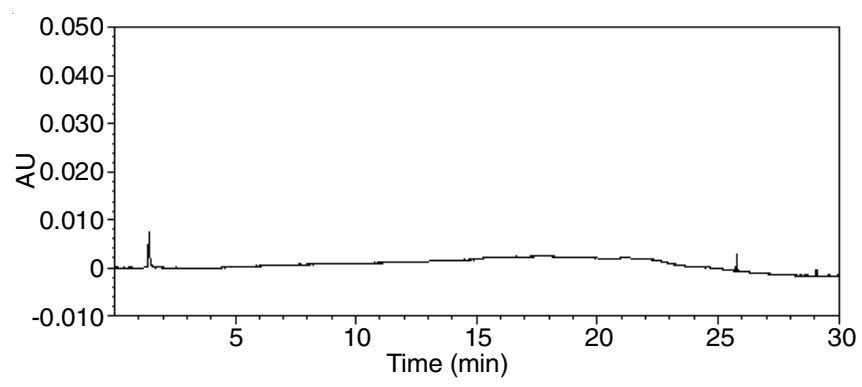

Fig. 12. Clopidogrel, rosuvastatin, aspirin tablets placebo chromatogram

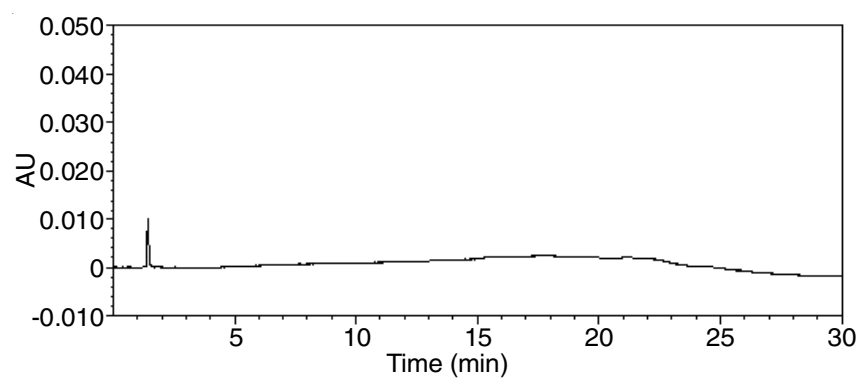

Fig. 13. Ezetimibe and rosuvastatin tablets placebo chromatogram

\begin{tabular}{lccc}
\multicolumn{5}{c}{ TABLE-5 } \\
SPECIFICITY CONDITIONS AND RESULTS \\
\hline Name of stress and condition & $\begin{array}{c}\text { Degradation } \\
(\%)\end{array}$ & $\begin{array}{c}\text { Purity } \\
\text { angle }\end{array}$ & $\begin{array}{c}\text { Purity } \\
\text { threshold }\end{array}$ \\
\hline \multicolumn{4}{c}{ Clopidogrel, Aspirin, Rosuvastatin test sample } \\
\hline Acid stress $/ 1 \mathrm{~N}-60^{\circ} \mathrm{C} / 90 \mathrm{~min}$ & 6.9 & 0.073 & 0.255 \\
Base stress $/ 1 \mathrm{~N}-60^{\circ} \mathrm{C} / 2 \mathrm{~h}$ & 1.7 & 0.071 & 0.309 \\
Peroxide stress $/ 3 \%-0{ }^{\circ} \mathrm{C} / 1 \mathrm{~h}$ & 10.9 & 0.146 & 0.283 \\
Water stress- $70{ }^{\circ} \mathrm{C} / 2 \mathrm{~h}$ & 1.7 & 0.084 & 0.243 \\
Thermal $\left(80{ }^{\circ} \mathrm{C}\right.$ for $\left.6 \mathrm{~h}\right)$ & 13.7 & 0.094 & 0.255 \\
UV energy of 200 -watt $\mathrm{h} /{ }^{2} \mathrm{~m}$ & - & - & - \\
\hline \multicolumn{4}{c}{ Rosuvastatin and Ezetimibe test sample } \\
\hline Acid stress $/ 1 \mathrm{~N}-60^{\circ} \mathrm{C} / 90 \mathrm{~min}$ & 6.9 & 0.073 & 0.255 \\
Base stress $/ 1 \mathrm{~N}-60^{\circ} \mathrm{C} / 2 \mathrm{~h}$ & 1.7 & 0.071 & 0.309 \\
Peroxide stress $/ 3 \%-50{ }^{\circ} \mathrm{C} / 1 \mathrm{~h}$ & 10.9 & 0.146 & 0.283 \\
Water stress- $70{ }^{\circ} \mathrm{C} / 2 \mathrm{~h}$ & 1.7 & 0.084 & 0.243 \\
Thermal $\left(80{ }^{\circ} \mathrm{C}\right.$ for $\left.6 \mathrm{~h}\right)$ & 13.7 & 0.094 & 0.255 \\
UV energy of 200 -watt $\mathrm{h} /{ }^{2} \mathrm{~m}$ & - & - & - \\
\hline
\end{tabular}

TABLE-4

PREISION RESULTS

\begin{tabular}{|c|c|c|c|c|c|c|c|}
\hline \multirow{2}{*}{ Active name } & \multicolumn{6}{|c|}{ Precision sample preparation (\% content) } & \multirow{2}{*}{$\operatorname{RSD}(\%)$} \\
\hline & 1 & 2 & 3 & 4 & 5 & 6 & \\
\hline \multicolumn{8}{|c|}{ Clopidogrel, Aspirin, Rosuvastatin sample } \\
\hline Aspirin & 100.16 & 100.25 & 99.68 & 100.58 & 99.87 & 100.15 & 0.31 \\
\hline Rosuvastatin & 99.88 & 100.21 & 99.79 & 101.21 & 100.13 & 101.31 & 0.67 \\
\hline Clopidogrel & 101.25 & 100.12 & 100.61 & 99.76 & 99.86 & 100.56 & 0.56 \\
\hline \multicolumn{8}{|c|}{ Rosuvastatin and Ezetimibe sample } \\
\hline Rosuvastatin & 101.20 & 100.10 & 100.31 & 101.02 & 100.54 & 100.26 & 0.44 \\
\hline Ezetimibe & 100.13 & 99.99 & 100.15 & 100.9 & 101.58 & 100.37 & 0.65 \\
\hline
\end{tabular}

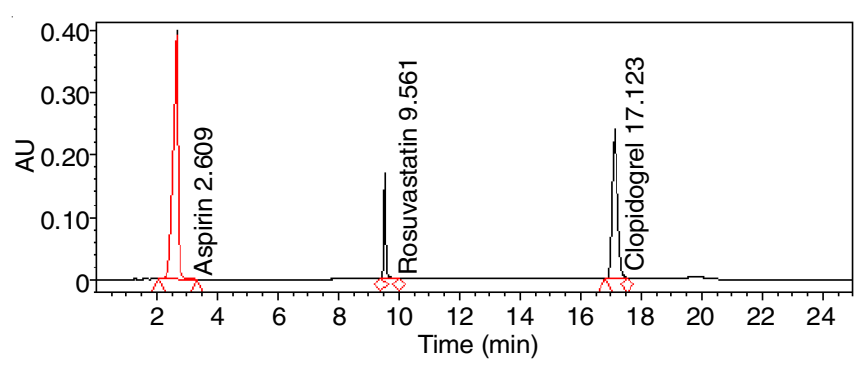

Fig. 14. Aspirin, rosuvastatin, clopidogrel test sample chromatogram

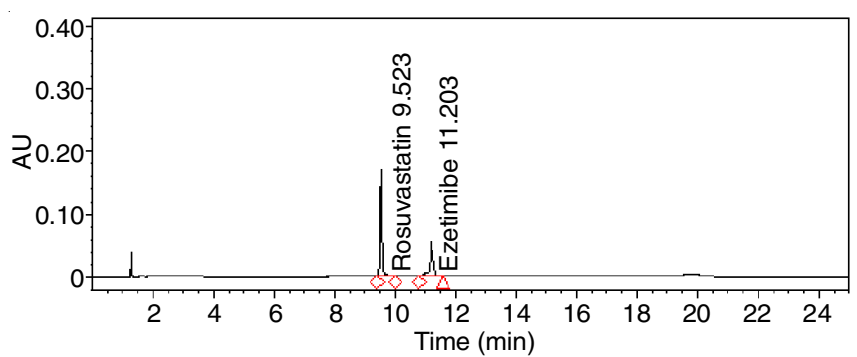

Fig. 15. Ezetimibe and rosuvastatin test sample chromatogram

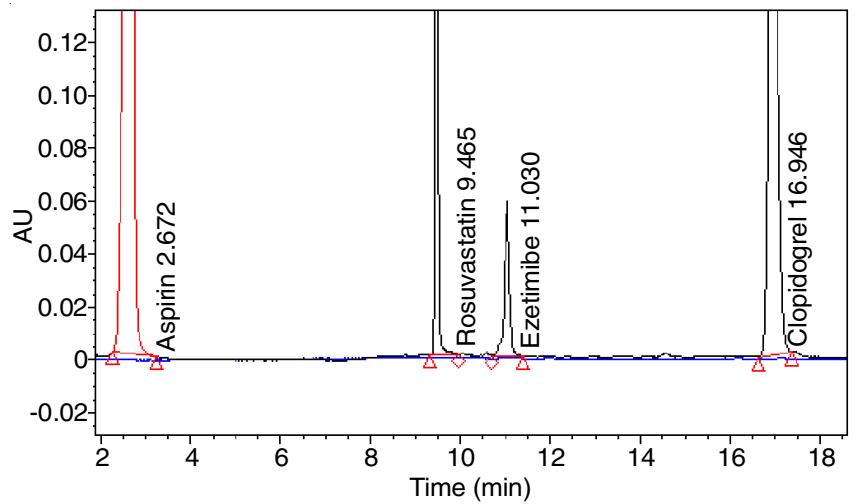

Fig. 16. Blank and standard overlay chromatogram

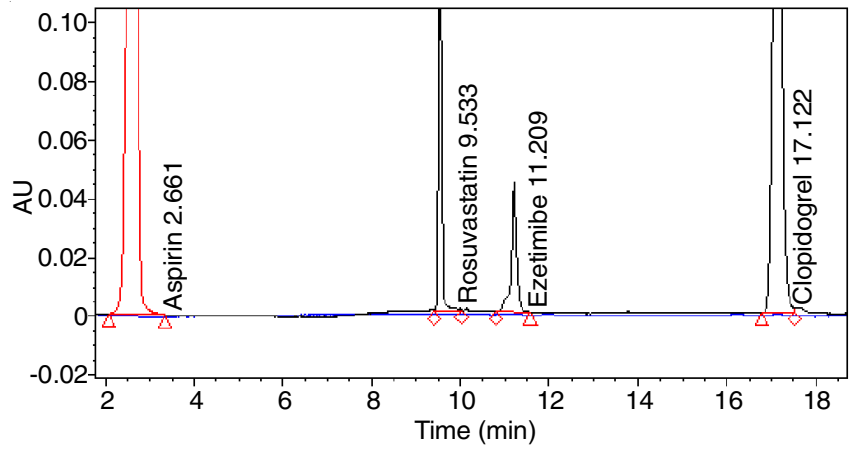

Fig. 17. Placebo and standard overlay chromatogram 


\begin{tabular}{|c|c|c|c|c|c|c|}
\hline \multicolumn{7}{|c|}{$\begin{array}{c}\text { TABLE-6 } \\
\text { SPECIFICITY IMPURITY RESULTS }\end{array}$} \\
\hline \multirow{2}{*}{ Stress condition } & \multicolumn{2}{|c|}{ Peak-1 } & \multicolumn{2}{|c|}{ Peak-2 } & \multicolumn{2}{|c|}{ Peak-3 } \\
\hline & RT (min) & Area $(\%)$ & RT (min) & Area $(\%)$ & $\mathrm{RT}(\min )$ & Area $(\%)$ \\
\hline \multicolumn{7}{|c|}{ Clopidogrel, aspirin, rosuvastatin test sample } \\
\hline Acid & 6.547 & 6.1 & 14.566 & 4.6 & 20.866 & 2.9 \\
\hline Base & 6.576 & 6.3 & 14.564 & 4.8 & ND & ND \\
\hline Peroxide & 6.573 & 5.9 & ND & ND & 20.863 & 2.8 \\
\hline Thermal & ND & ND & 14.569 & 4.6 & 20.869 & 30 \\
\hline UV & 6.533 & 6.0 & 14.567 & 4.9 & ND & ND \\
\hline Water & 6.566 & 5.9 & 14.547 & 4.4 & ND & ND \\
\hline \multicolumn{7}{|c|}{ Rosuvastatin and Ezetimibe test sample } \\
\hline Acid & 6.503 & 6.2 & 14.543 & 5.1 & 20.836 & 2.8 \\
\hline Base & 6.506 & 5.8 & 14.563 & 4.9 & ND & ND \\
\hline Peroxide & 6.543 & 6.3 & ND & ND & ND & ND \\
\hline Thermal & ND & ND & 14.561 & 4.9 & 20.800 & 2.8 \\
\hline UV & ND & ND & ND & ND & 20.807 & 2.7 \\
\hline Water & ND & ND & 14.560 & 5.0 & 20.862 & 3.0 \\
\hline
\end{tabular}

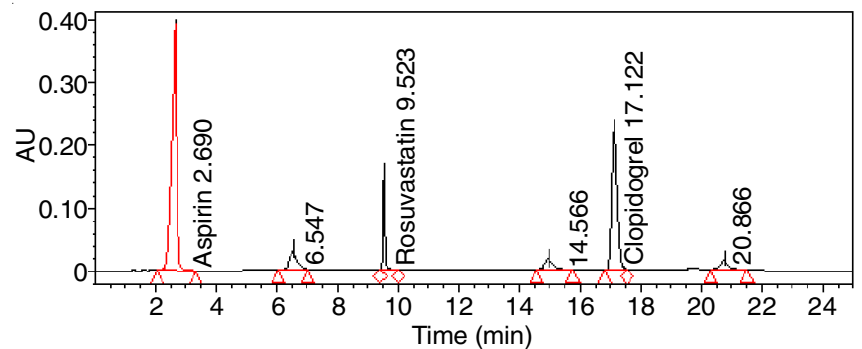

Fig. 18. Aspirin, rosuvastatin, clopidogrel acid degradation chromatogram

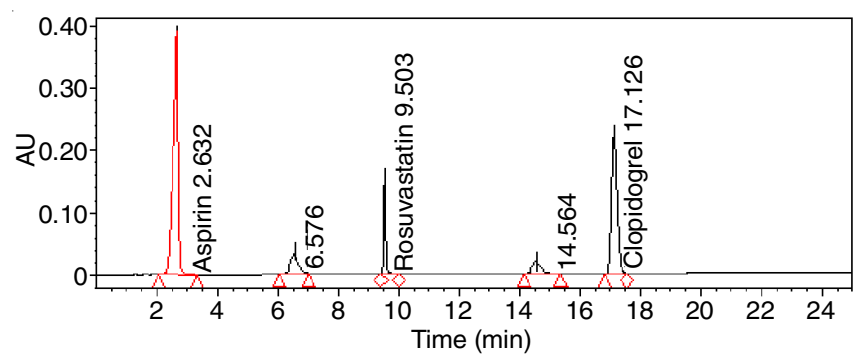

Fig. 19. Aspirin, rosuvastatin, clopidogrel base degradation chromatogram

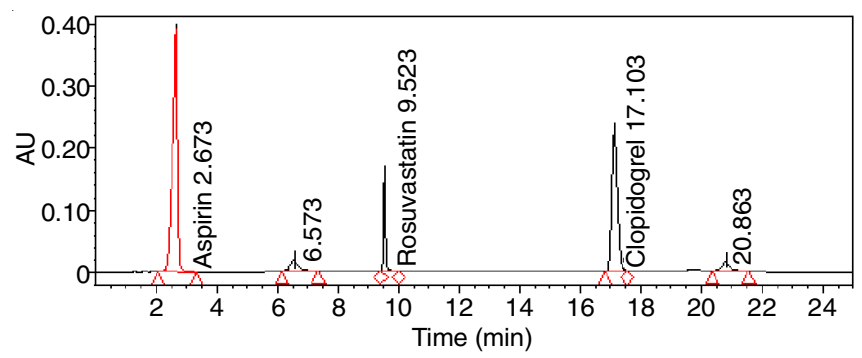

Fig. 20. Aspirin, rosuvastatin, clopidogrel peroxide degradation chromatogram

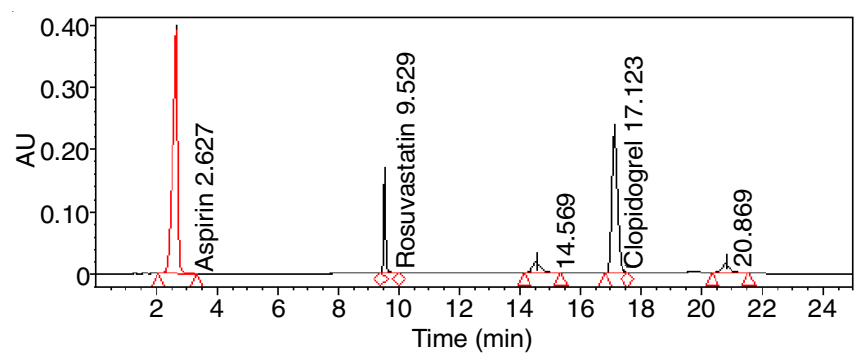

Fig. 21. Aspirin, rosuvastatin, clopidogrel thermal degradation chromatogram

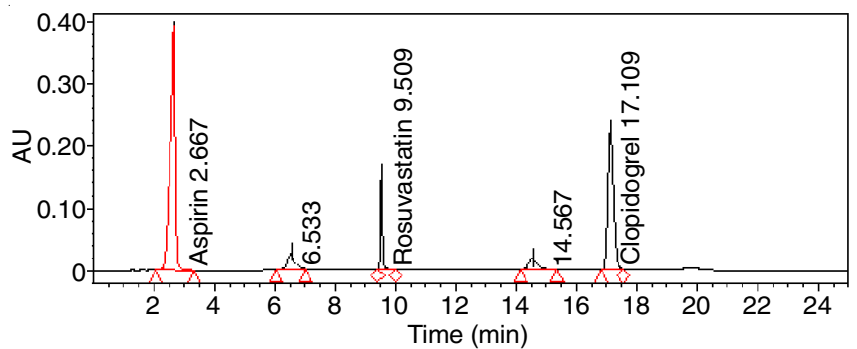

Fig. 22. Aspirin, rosuvastatin, clopidogrel UV degradation chromatogram

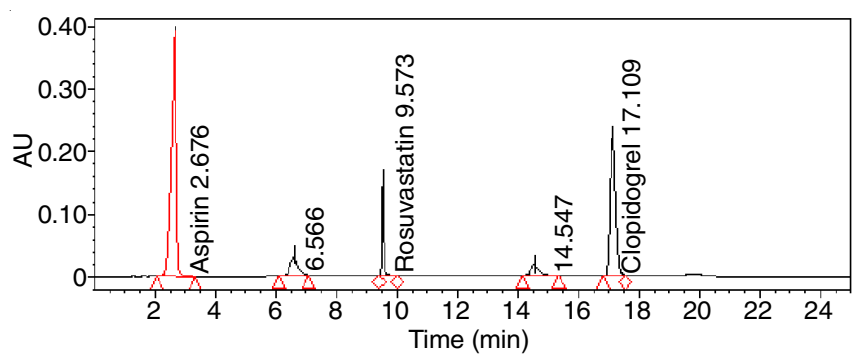

Fig. 23. Aspirin, rosuvastatin, clopidogrel water degradation chromatogram

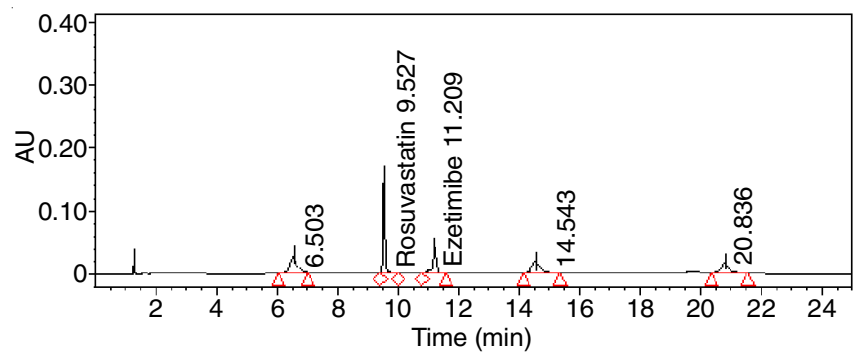

Fig. 24. Ezetimibe and rosuvastatin acid degradation chromatogram

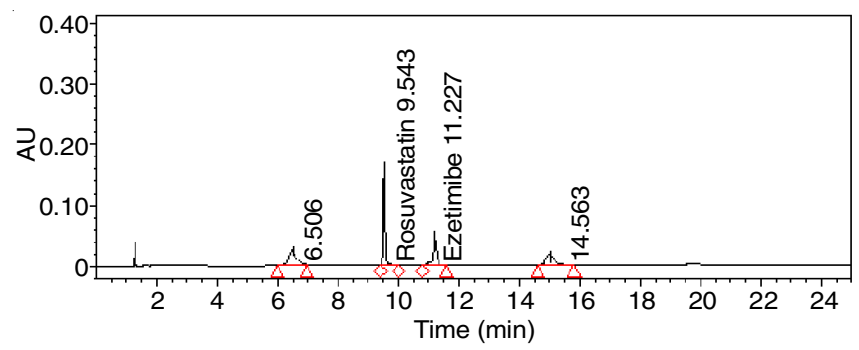

Fig. 25. Ezetimibe and rosuvastatin base degradation chromatogram 


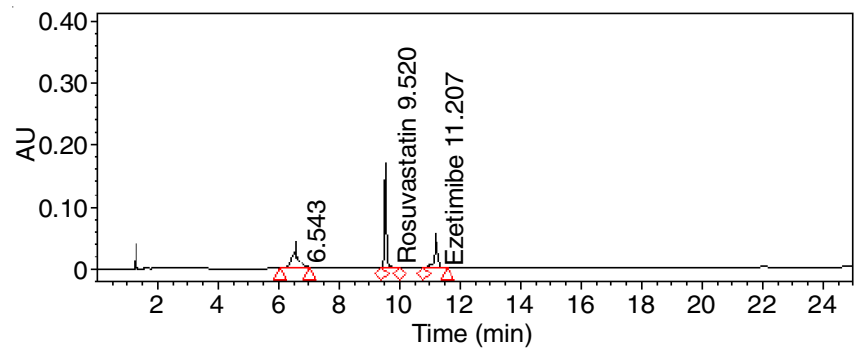

Fig. 26. Ezetimibe and rosuvastatin peroxide degradation chromatogram

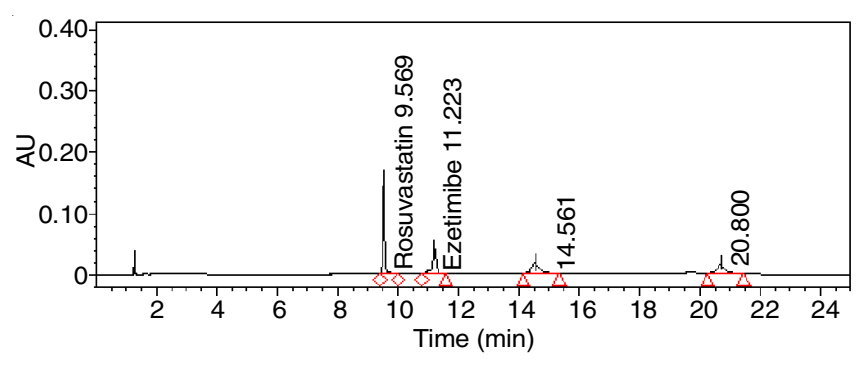

Fig. 27. Ezetimibe and rosuvastatin thermal degradation chromatogram

prepared standard stock solution was used to prepare all linearity levels. All linearity levels were injected into the chromatographic system. Correlation coefficient value was calculated and

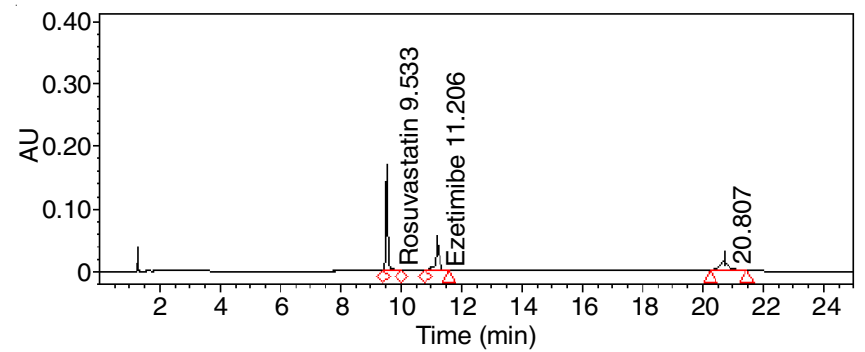

Fig. 28. Ezetimibe and rosuvastatin UV degradation chromatogram

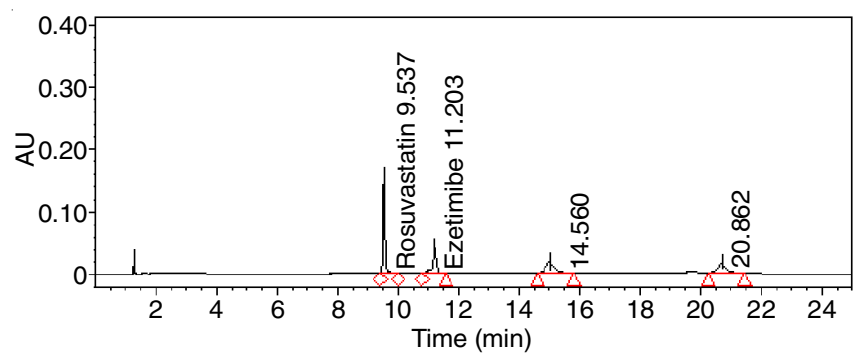

Fig. 29. Ezetimibe and rosuvastatin water degradation chromatogram

found to be satisfactory i.e. above 0.999 for all components. Linearity graph was plotted with concentration and area values and the linearity results are shown in Table-7.

\begin{tabular}{ccc|cc|ccc|c}
\multicolumn{10}{c}{ TABLE-7 } \\
\multicolumn{10}{c}{ LINEARITY RESULTS } \\
\hline Linearity \\
level
\end{tabular}

\begin{tabular}{|c|c|c|c|c|c|c|c|c|c|}
\hline \multicolumn{10}{|c|}{$\begin{array}{c}\text { TABLE-8 } \\
\text { ACCURACY RESULTS }\end{array}$} \\
\hline \multirow[b]{2}{*}{ Level } & \multicolumn{9}{|c|}{ Clopidogrel, Aspirin and Rosuvastatin Accuracy results } \\
\hline & $\begin{array}{l}\text { Qty. added } \\
\text { (ppm) }\end{array}$ & $\begin{array}{c}\text { Qty. } \\
\text { recovered } \\
\text { (ppm) }\end{array}$ & $\begin{array}{l}\text { Recovery } \\
(\%)\end{array}$ & $\begin{array}{l}\text { Qty. added } \\
\text { (ppm) }\end{array}$ & $\begin{array}{c}\text { Qty. } \\
\text { recovered } \\
(\mathrm{ppm})\end{array}$ & $\begin{array}{l}\text { Recovery } \\
(\%)\end{array}$ & $\begin{array}{l}\text { Qty. added } \\
\text { (ppm) }\end{array}$ & $\begin{array}{c}\text { Qty. } \\
\text { recovered } \\
(\mathrm{ppm})\end{array}$ & $\begin{array}{l}\text { Recovery } \\
(\%)\end{array}$ \\
\hline & \multicolumn{3}{|c|}{ Aspirin } & \multicolumn{3}{|c|}{ Rosuvastatin } & \multicolumn{3}{|c|}{ Clopidogrel } \\
\hline \multirow{4}{*}{$50 \%$} & 37.52 & 37.49 & 99.92 & 5.01 & 5.05 & 100.80 & 5.09 & 5.12 & 100.59 \\
\hline & 37.51 & 37.53 & 100.05 & 5.03 & 5.04 & 100.20 & 5.04 & 5.06 & 100.40 \\
\hline & 37.52 & 37.54 & 100.05 & 5.02 & 5.03 & 100.20 & 5.03 & 5.05 & 100.40 \\
\hline & 75.01 & 75.06 & 100.07 & 10.10 & 10.14 & 100.40 & 10.04 & 10.06 & 100.20 \\
\hline \multirow{3}{*}{$100 \%$} & 75.06 & 75.03 & 99.96 & 10.13 & 10.11 & 99.80 & 10.06 & 10.09 & 100.30 \\
\hline & 75.04 & 75.07 & 100.04 & 10.09 & 10.10 & 100.10 & 10.08 & 10.02 & 99.40 \\
\hline & 112.50 & 112.53 & 100.03 & 15.03 & 15.10 & 100.47 & 15.02 & 15.09 & 100.47 \\
\hline \multirow{4}{*}{$150 \%$} & 112.53 & 112.55 & 100.02 & 15.04 & 15.10 & 100.40 & 15.04 & 15.07 & 100.20 \\
\hline & 112.51 & 112.57 & 100.05 & 15.01 & 15.08 & 100.47 & 15.03 & 15.04 & 100.07 \\
\hline & \multicolumn{6}{|c|}{ Rosuvastatin and ezetimibe test sample } & & & \\
\hline & \multicolumn{3}{|c|}{ Rosuvastatin } & \multicolumn{3}{|c|}{ Ezetimibe } & & & \\
\hline \multirow{4}{*}{$50 \%$} & 5.02 & 5.06 & 100.80 & 37.50 & 37.53 & 100.08 & & & \\
\hline & 5.04 & 5.07 & 100.60 & 37.54 & 37.50 & 99.89 & & & \\
\hline & 5.01 & 5.06 & 101.00 & 37.55 & 37.54 & 99.97 & & & \\
\hline & 10.11 & 10.15 & 100.40 & 75.06 & 75.09 & 100.04 & & & \\
\hline \multirow[t]{2}{*}{$100 \%$} & 10.10 & 10.13 & 100.30 & 75.03 & 75.04 & 100.01 & & & \\
\hline & 10.08 & 10.10 & 100.20 & 75.08 & 75.01 & 99.91 & & & \\
\hline \multirow{3}{*}{$150 \%$} & 15.05 & 15.11 & 100.40 & 112.51 & 112.56 & 100.04 & & & \\
\hline & 15.04 & 15.07 & 100.20 & 112.55 & 112.50 & 99.96 & & & \\
\hline & 15.06 & 15.03 & 99.80 & 112.54 & 112.58 & 100.04 & & & \\
\hline
\end{tabular}


Accuracy: Accuracy was performed with three different concentration levels. A 50, 100 and $150 \%$ accuracy levels were conducted. Placebo stock solutions were spiked to API stock solutions. Clopidogrel, aspirin, rosuvastatin samples were prepared separately and rosuvastatin and ezetimibe accuracy samples were prepared separately. Accuracy results were calculated and results $\%$ recovery was satisfactory. Percentage recovery result was found to be between $97 \%$ to $103 \%$. Table- 8 shown the accuracy levels for clopidogrel, aspirin and rosuvastatin combination products and rosuvastatin and ezetimibe combination.

Ruggedness: Ruggedness was performed for solution stability store conditions at room temperature and refrigerator. Mobile phase stability evaluated at room temperature. Initially prepared two samples (retained from precision analysis) were kept at room temperature and refrigerator and conducted the study at day-1 (24 h) and day-3 (72 h). Mobile phase stability study evaluated at day-1 (24 h) and day-3 (72 h). Tables 9 and 10 represented the ruggedness results.

Robustness: Robustness was performed for mobile phase flow rate variation, column oven temperature variation and filter validation. All the variations results (Tables 11 and 12) were found to be satisfactory.

\section{Conclusion}

A simple HPLC method was developed for the quantification of four drug components in solid dosage forms. Aspirin, clopidogrel, rosuvastatin and ezetimibe were quantified with

\begin{tabular}{|c|c|c|c|c|}
\hline \multicolumn{5}{|c|}{$\begin{array}{c}\text { TABLE-9 } \\
\text { SOLUTION STABILITY RESULTS }\end{array}$} \\
\hline \multirow{2}{*}{ Duration } & \multicolumn{2}{|c|}{ Sample solution-1 } & \multicolumn{2}{|c|}{ Sample solution- 2} \\
\hline & Actual & Variation $(\%)$ & Actual & Variation $(\%)$ \\
\hline \multicolumn{5}{|c|}{ Aspirin } \\
\hline Initial & 101.54 & NA & 100.56 & NA \\
\hline Day-1 & 100.92 & 0.6 & 100.32 & 0.2 \\
\hline Day-3 & 100.26 & 1.3 & 100.34 & 0.2 \\
\hline \multicolumn{5}{|c|}{ Rosuvastatin (clopidogrel, aspirin, rosuvastatin tablets) } \\
\hline Initial & 100.68 & NA & 99.98 & NA \\
\hline Day-1 & 99.89 & 0.79 & 101.00 & 1.02 \\
\hline Day-3 & 101.60 & 0.92 & 100.06 & 0.08 \\
\hline \multicolumn{5}{|c|}{ Rosuvastatin (rosuvastatin and ezetimibe tablets) } \\
\hline Initial & 100.14 & NA & 100.65 & NA \\
\hline Day-1 & 99.98 & 0.16 & 100.31 & 0.34 \\
\hline Day-3 & 101.00 & 0.86 & 99.87 & 0.78 \\
\hline \multicolumn{5}{|c|}{ Ezetimibe } \\
\hline Initial & 100.14 & NA & 100.65 & NA \\
\hline Day-1 & 99.98 & 0.16 & 100.31 & 0.34 \\
\hline Day-3 & 101.00 & 0.86 & 99.87 & 0.78 \\
\hline \multicolumn{5}{|c|}{ Clopidogrel } \\
\hline Initial & 100.14 & NA & 100.65 & NA \\
\hline Day-1 & 99.98 & 0.16 & 100.31 & 0.34 \\
\hline Day-3 & 101.00 & 0.86 & 99.87 & 0.78 \\
\hline
\end{tabular}

stability indicating HPLC method. Method validation was performed as per ICH Q2, USFDA guidance documents. Precision results \% of assay and \%RSD values was within in the limit. Linearity correlation coefficient above 0.999 for all the four

TABLE-10

SOLUTION STABILITY RESULTS

\begin{tabular}{|c|c|c|c|c|c|c|c|c|c|c|}
\hline \multirow{3}{*}{ Duration } & \multicolumn{6}{|c|}{ Clopidogrel, aspirin, rosuvastatin tablets } & \multicolumn{4}{|c|}{ Rosuvastatin, Ezetimibe tablets } \\
\hline & \multicolumn{2}{|c|}{ Aspirin } & \multicolumn{2}{|c|}{ Rosuvastatin } & \multicolumn{2}{|c|}{ Clopidogrel } & \multicolumn{2}{|c|}{ Rosuvastatin } & \multicolumn{2}{|c|}{ Ezetimibe } \\
\hline & $\begin{array}{l}\text { Tailing } \\
\text { factor }\end{array}$ & $\operatorname{RSD}(\%)$ & $\begin{array}{l}\text { Tailing } \\
\text { factor }\end{array}$ & $\operatorname{RSD}(\%)$ & $\begin{array}{l}\text { Tailing } \\
\text { factor }\end{array}$ & $\operatorname{RSD}(\%)$ & $\begin{array}{l}\text { Tailing } \\
\text { factor }\end{array}$ & $\operatorname{RSD}(\%)$ & $\begin{array}{l}\text { Tailing } \\
\text { factor }\end{array}$ & $\operatorname{RSD}(\%)$ \\
\hline Initial & 1.2 & 0.59 & 1.3 & 0.61 & 1.4 & 0.61 & 1.4 & 0.61 & 1.2 & 0.71 \\
\hline Day-1 & 1.4 & 0.61 & 1.1 & 0.57 & 1.2 & 0.54 & 1.2 & 0.57 & 1.5 & 0.59 \\
\hline Day-3 & 1.1 & 0.54 & 1.4 & 0.61 & 1.6 & 0.58 & 1.6 & 0.53 & 1.4 & 0.64 \\
\hline
\end{tabular}

TABLE-11

ROBUSTNESS RESULTS

\begin{tabular}{|c|c|c|c|c|c|c|c|c|c|c|c|}
\hline \multirow{2}{*}{\multicolumn{2}{|c|}{ Parameter }} & \multicolumn{2}{|c|}{ Aspirin } & \multicolumn{2}{|c|}{$\begin{array}{l}\text { Rosuvastatin } \\
\text { (clopidogrel } \\
\text { combination) }\end{array}$} & \multicolumn{2}{|c|}{$\begin{array}{c}\text { Rosuvastatin } \\
\text { (ezetimibe } \\
\text { combination) }\end{array}$} & \multicolumn{2}{|c|}{ Clopidogrel } & \multicolumn{2}{|c|}{ Ezetimibe } \\
\hline & & $\begin{array}{l}\text { Tailing } \\
\text { factor }\end{array}$ & $\begin{array}{l}\text { \%RSD } \\
\text { (5 inj.) }\end{array}$ & $\begin{array}{l}\text { Tailing } \\
\text { factor }\end{array}$ & $\begin{array}{l}\text { \%RSD } \\
\text { (5 inj.) }\end{array}$ & $\begin{array}{l}\text { Tailing } \\
\text { factor }\end{array}$ & $\begin{array}{l}\text { \%RSD } \\
\text { (5 inj.) }\end{array}$ & $\begin{array}{l}\text { Tailing } \\
\text { factor }\end{array}$ & $\begin{array}{l}\text { \%RSD } \\
\text { (5 inj.) }\end{array}$ & $\begin{array}{l}\text { Tailing } \\
\text { factor }\end{array}$ & $\begin{array}{l}\% \text { RSD } \\
\text { (5 inj.) }\end{array}$ \\
\hline \multirow{2}{*}{$\begin{array}{l}\begin{array}{l}\text { Flow rate } \\
(\mathrm{mL} / \mathrm{min})\end{array} \\
\end{array}$} & 0.8 & 1.0 & 0.63 & 1.1 & 0.45 & 1.1 & 0.61 & 1.2 & 0.59 & 1.3 & 0.60 \\
\hline & 1.2 & 0.9 & 0.59 & 1.0 & 0.16 & 1.0 & 0.54 & 1.1 & 0.68 & 1.6 & 0.63 \\
\hline \multirow{2}{*}{$\begin{array}{l}\text { Temp. } \\
\left({ }^{\circ} \mathrm{C}\right)\end{array}$} & 25 & 1.1 & 0.14 & 1.2 & 0.61 & 0.9 & 0.16 & 1.4 & 0.61 & 1.3 & 0.54 \\
\hline & 35 & 1.0 & 1.0 & 0.9 & 0.56 & 1.1 & 1.13 & 1.3 & 0.70 & 1.2 & 0.59 \\
\hline
\end{tabular}

TABLE-12

EFFECT OF $0.45 \mu \mathrm{m}$ PVDF FILTERS ON STANDARD SOLUTION

\begin{tabular}{|c|c|c|c|c|c|c|c|c|c|c|}
\hline \multirow{2}{*}{$\begin{array}{l}\text { Standard } \\
\text { solution }\end{array}$} & \multicolumn{2}{|c|}{ Aspirin } & \multicolumn{2}{|c|}{$\begin{array}{c}\text { Rosuvastatin } \\
\text { (clopidogrel } \\
\text { combination) }\end{array}$} & \multicolumn{2}{|c|}{$\begin{array}{l}\text { Rosuvastatin (ezetimibe } \\
\text { combination) }\end{array}$} & \multicolumn{2}{|c|}{ Clopidogrel } & \multicolumn{2}{|c|}{ Ezetimibe } \\
\hline & $\begin{array}{l}\text { \% Assay } \\
(\mathrm{w} / \mathrm{w})\end{array}$ & $\begin{array}{l}\text { Difference } \\
(\%)\end{array}$ & $\begin{array}{c}\text { \% Assay } \\
(\mathrm{w} / \mathrm{w})\end{array}$ & $\begin{array}{c}\text { Difference } \\
(\%)\end{array}$ & $\begin{array}{l}\text { \% Assay } \\
(\mathrm{w} / \mathrm{w})\end{array}$ & $\begin{array}{c}\text { Difference } \\
(\%)\end{array}$ & $\begin{array}{l}\text { \% Assay } \\
(\mathrm{w} / \mathrm{w})\end{array}$ & $\begin{array}{l}\text { Difference } \\
(\%)\end{array}$ & $\begin{array}{l}\text { \% Assay } \\
(\mathrm{w} / \mathrm{w})\end{array}$ & $\begin{array}{c}\text { Difference } \\
(\%)\end{array}$ \\
\hline Centrifuged & 100.80 & NA & 103.16 & NA & 100.77 & NA & 101.30 & NA & 100.61 & NA \\
\hline $\begin{array}{c}0.45 \mu \mathrm{m} \\
\text { PVDF filter }\end{array}$ & 100.63 & 0.17 & 101.15 & 2.01 & 100.10 & 0.67 & 100.25 & 1.05 & 99.81 & 0.80 \\
\hline
\end{tabular}


components was observed. Specificity confirmed no interference with placebo, diluent and unknown impurity peaks. Ruggedness and robustness results confirmed the HPLC method compatibility in different systems and laboratories. Eventually, this HPLC method can be applied for regular medicinal product analysis.

\section{ACKNOWLEDGEMENTS}

The authors are thankful to MANASA Life Sciences, Hyderabad, India for providing technical support.

\section{CONFLICT OF INTEREST}

The authors declare that there is no conflict of interests regarding the publication of this article.

\section{REFERENCES}

1. N. Khalaf, C. Yuan, T. Hamada, Y. Cao, A. Babic, V. Morales-Oyarvide, P. Kraft, K. Ng, E. Giovannucci, S. Ogino, M. Stampfer, B.B. Cochrane, J.E. Manson, C.B. Clish, A.T. Chan, C.S. Fuchs and B.M. Wolpin, Gastroenterology, 154, 1380 (2018); https://doi.org/10.1053/j.gastro.2017.12.001.

2. R. Fernandez-Jimenez, J. Latina, R. Hajjar, V. Fuster, T. Wang and W. Blot, J. Am. Coll. Cardiol., 71, A1892 (2018); https://doi.org/10.1016/S0735-1097(18)32433-1.

3. K. Vyshnavi, M. Bhashetty, N. Swain, M. Venkataswamy and A. Ramesh, Res. J. Pharm. Dos. Forms Technol., 9, 45 (2017); https://doi.org/10.5958/0975-4377.2017.00009.X.

4. T. Zhu, B. Parker, T. Wojtkowski, T. Nishimura, J.P. Garg, D. Han, O. Fisniku and J. Keirns, Clin. Pharmacokinet., 56, 747 (2017); https://doi.org/10.1007/s40262-016-0474-4.
5. A.V. Khera, O.V. Demler, S.J. Adelman, H.L. Collins, R.J. Glynn, P.M. Ridker, D.J. Rader and S. Mora, Circulation, 135, 2494 (2017); https://doi.org/10.1161/CIRCULATIONAHA.116.025678.

6. S. Takase and T. Matoba, Arterioscler. Thromb. Vasc. Biol., 37, e54 (2017); https://doi.org/10.1161/ATVBAHA.117.309301.

7. E.T. Kato, C.P. Cannon, M.A. Blazing, E. Bohula, S. Guneri, J.A. White, S.A. Murphy, J.G. Park, E. Braunwald and R.P. Giugliano, J. Am. Heart Assoc., 6, e006901 (2017); https://doi.org/10.1161/JAHA.117.006901.

8. J. Schmucker, H. Wienbergen, A. Fach, L.M. Marin, D. Garstka, J. Stehmeier, E. Fiehn and R. Hambrecht, Eur. Heart J., 38(Suppl. 1), ehx501.263 (2017); https://doi.org/10.1093/eurheartj/ehx501.263.

9. T.K. Bergmann, K. Agergaard, M. Mau-Sørensen, T.B. Stage, T.L. Jørgensen, R.E. Hassel, K.D. Steffensen, J.W. Pedersen, M.L. Milo, S.H. Poulsen, A. Pottegård, J. Hallas and K. Brosen, Clin. Ther, 39, e61 (2017); https://doi.org/10.1016/j.clinthera.2017.05.189.

10. H. Kahma, A.M. Filppula, M. Neuvonen, E.K. Tarkiainen, A. Tornio, M.T. Holmberg, M.K. Itkonen, M. Finel, P.J. Neuvonen, M. Niemi and J.T. Backman, Drug Metab. Dispos., 46, 141 (2018); https://doi.org/10.1124/dmd.117.078162.

11. A. Bhadoriya, M. Sanyal, P.A. Shah and P.S. Shrivastav, Biomed. Chromatogr., 32, 4291 (2018); https://doi.org/10.1002/bmc.4291.

12. H. Kim, H.Y. Choi, Y.H. Kim, K.S. Bae, J. Jung, H. Son and H.S. Lim, Drug Des. Devel. Ther, 12, 815 (2018); https://doi.org/10.2147/DDDT.S158408.

13. D. Sireesha, M.L. Monika and V. Bakshi, Asian J. Pharm. Anal., 7, 135 (2017); https://doi.org/10.5958/2231-5675.2017.00021.7.

14. J. Yadav and A. Sharma, Pharma Tutor, 5, 35 (2017).

15. A.S. Sankar, P. Shanmugasundaram and V. Ravichandiran, Curr. Anal. Chem., 13, 386 (2017); https://doi.org/10.2174/1573411013666170127163707. 